hace que con solo asomarse a ellas todos los individuos queden comunicados entre sí. Los ejemplos son innumerables: recordemos la secuencia en la que la niña abandonada inicia un concierto de gritos que hace que en pocos segundos las ventanas se llenen de rostros comprometidos con el suceso. También al anciano paralítico le basta con acudir a su vecina en donde el operario vive también de cara al exterior. Las aulas se destacan también por sus enormes ventanas y a dos niños les basta con subirse uno sobre el otro para, a través de una ventana, contemplar extasiados cómo la mujer desnuda inicia su aseo. La innecesaria secuencia de Gregory es también una grosera prueba de este privilegio del exterior. La promiscuidad parece ser esencial a la convivencia y por ello los interiores aparecen tan solo como sutiles prolongaciones de fundamental espacio exterior. El universo es un universo de niños, un universo masculino. ${ }^{3}$

La cámara respeta coherentemente esta puesta en escena. El primer plano es excluido del filme y toda la narración parece construida sobre un único plano general que renuncia a destacar objetos o personas de esta equitativa comunidad.

Es indudable que puede discutirse la realidad de los niños de Truffaut, para todos es obvio que muchos de los componentes menos luminosos de la condición humana están ausentes del pueblo de Thiers y de sus niños. La crueldad, por ejemplo, ha huido del universo y cualquier niño de La piel dura lloraría de espanto con solo ver la lucha entre el alacrán y las hormigas que divierte a los niños de La pandilla salvaje. Lo que sí es discutible es que la "irrealidad" deba aceptarse como criterio válido para enjuiciar el filme. Lo evidente es que $L a$ piel dura logra transmitir una visión personal de la niñez que se integra plenamente a un tratamiento formal y por ello, como auguraba Jean Luc Godard, ya estamos hablando de "los niños de Truffaut como decimos los lanceros de Bengala, los reyes de la mafia o los locos del volante".

Originalmente publicado en Hablemos de cine. Año XIII, núm. 69. Lima, 1977-1978, pp. 50-51.

${ }^{2}$ No solo el psicoanálisis encuentra esta diferente valoración del espacio y su relación con los sexos. Un autor como Philipp Lersch dice en su libro Sobre la esencia de los sexos: "Con respecto al mundo esto no significa sino que la mujer vive más en un mundo CERRADO; hombre en un mundo ABIERTO [ . ] La mujer perman hombés circunscrita al B ce más circun mund poner el espacio".

${ }^{3}$ La comunidad de los niños de Thiers es fundamentalmente masculina. Incluso el filme parece encaminarse hacia el descubrimiento de la pareja. Como grupo, colegio anuncia su transformación en colegio mixto, $y$ en forma individual la historia termina con la aparición de las niñas gracias a un paseo vocacional y el descubrimiento de la atracción sexual entre dos de los protagonistas.

\title{
BUSCANDO A MR. GOODBAR \\ (Looking for Mr. Goodbar, 1977) de Richard Brooks
}

\section{Constantino Carvallo Rey}

ichard Brooks ha sido definido muchas veces como un realizador preocupado fundamentalmente por las situaciones éticas. Jean Luc Godard ha destacado los dos elementos que tejen la filmografía brooksiana: de un lado, "la aprehensión directa y física de lo real", de otro, y en armoniosa unidad, "la distancia reflexiva [...] la sabiduría”. Sin embargo, un cierto utopismo, ingenua creencia en el triunfo del bien, unido a una excesiva dependencia al "esquema de la intriga", hacían que su primera época se caracterizase por una débil penetración crítica, dejando "el sistema social atizado muy tangencialmente”. Es un personaje femenino, y la reflexión sobre la pareja, lo que marca en su obra, el resquebrajamiento, anunciado ya en $A$ sangre fría, de su antiguo sueño americano. La Mary Wilson de El amargo fin, primer intento de acercamiento a la mujer, funda la madurez pesimista a la que ha arribado el viejo realizador de Lord Jim.

Buscando a Mr. Goodbar es, casi diez años más tarde, el segundo encuentro de Brooks con el universo femenino. Esta vez, la sexualidad, la búsqueda del placer, el enfrentamiento de los sexos, constituyen, abiertamente, el centro de reflexión. Ya el propio Marx, en los albores de su investigación, encontraba que en la relación inmediata, voluptuosa y natural, del hombre con la mujer puede evidenciarse, "de manera sensible, reducida a un hecho visible, la infinita degradación de la sociedad". El empobrecimiento y la despersonalización de la vida erótica, aparecen para el joven Marx como la praxis de la enajenación. La Therese Dunn, en busca de Mr. Goodbar, ${ }^{2}$ sirve a Richard Brooks para mostrar la moderna degradación de la vida erótica y para sepultar definitivamente, en la década del setenta, el sueño de la bella América.

Teniendo como base una mediocre novela de Judith Rossner, el filme ubica su historia entre dos años nuevos (19751976), el tiempo en el cual transcurre el ciclo fatal de Therese. Maestra de niños sordos durante el día, se transforma al caer la noche en Terry la Aventurera, hambrienta de estímulos tras haber pasado gran parte de su vida distanciada de su propio cuerpo, paralizado por la escoliosis. El filme introduce al personaje cuando inicia una suerte de educación sentimental, obtenida de su relación con el profesor Martín. Aprende de él su sexismo y una ironía distante frente a formas de relación fundadas en afectos y compromisos. Su frase "no soporto la compañía de la mujer que acabo de gozar" marca para Therese el fin de su aprendizaje. En adelante, ingresa a la "Tierra de la Cópula", donde desborda esa lujuria incubada durante años de parálisis. Lujuria ansiosa que Therese no sabe si es producto de su mente o de su cuerpo.

La vida nocturna, y concretamente el bar, se convierte en un auténtico prostíbulo para mujeres. Aparece, en palabras de la propia J. Rossner, como un "coto de caza de varón". Richard Brooks muestra su sórdida visión de una forma de vida nueva, abierta a la mujer por los movimientos de liberación. Esta visión, sin duda exagerada, coincide en lo esencial con lo señalado por la propia $\mathrm{S}$. Sontag, quien afirma que "el sexo por sí solo no libera", "la emancipación sexual de la mujer - dice- es una victoria superficial si la sexualidad a la que accede sigue siendo la misma [...], actos de mutua egomasturbación, fundados en una idea espúrea de la libertad". Es esta la tesis que Brooks muestra y no tenemos sino que recordar la primera noche de Therese viviendo sola, con la almohada entre las piernas, o el modo como son encuadradas las escenas eróticas, con los personajes separados; para entender esta inversión del machismo llevada a cabo por un personaje femenino 
que acepta al hombre como "un elemento accesorio inseparable del pene”. Y aquí el encuentro con Tony Lopanto (notable Richard Gere) cumbre de relación objetal, es el punto más alto del filme. Fálico y narcisista, Tony el Tamborillero es para Therese el espejo de su decadencia. Cuando decide cambiar de vida, suprimiendo la nocturna, ya es demasiado tarde y el fin llega en una impresionante secuencia que une orgasmo y muerte. Final un tanto insatisfactorio por la innecesaria presencia de la homosexualidad. Brooks completa su cuadro con la introducción del asesino, ejemplar por exageración, según Henry Miller, del problema sexual de nuestro tiempo, "emocionalmente impotente sólo puede entrar en contacto con el prójimo derramando su sangre".

Pero si Buscando a Mr. Goodbar resulta un muy buen filme es sobre todo por la madurez expresiva con que Brooks construye su película. Destierra por completo el primer plano y su penetración en los personajes está dada por la presencia física de estos en el interior de una sobria puesta en escena. $Y$ es especialmente en una dialéctica implacable, creada en el montaje, donde reposa la fuerza dramática de este filme. Se articula la planificación con una brusquedad que quiere impedir la continuidad fluida. El filme está pensado como la suma de una serie de secuencias cortas opuestas entre sí. Somos arrastrados violentamente, de la escuela a la casa, de esta al hospital, otra vez a la casa, de pronto en los bares, otra vez en la escuela, etcétera. Los planos y las secuencias se interrumpen súbitamente, sin que termine la acción, cortándose la banda sonora, la música y el movimiento de los personajes. La oposición entre el mundo diurno, ubicado sobre todo en el sereno y coloreado salón de clases, y el agitado mundo nocturno, centrado en los bares, es el eje principal de las esquizoides elipsis. Es de esta "rítmica", contradictoria y brutal, de donde emerge la violencia que traspasa todo el filme. A pesar de que la historia nos muestra a una Therese bastante tranquila y no llega a constituir un personaje angustiado, nosotros somos sobresaltados por esta violación del raccord, por esta continuidad brutal compuesta de enfrentamientos. Deuda especial de Brooks con el experimentado fotógrafo y realizador W. A. Fraker, quien ha logrado esta oposición entre los dos mundos en que se mueve Therese y, sobre todo, ha trabajado el lado nocturno con una maestría sorprendente. La composición del encuadre, gracias a la iluminación que distribuye las sombras, da la atmósfera de "noche de los sentidos" que percibimos en la historia.

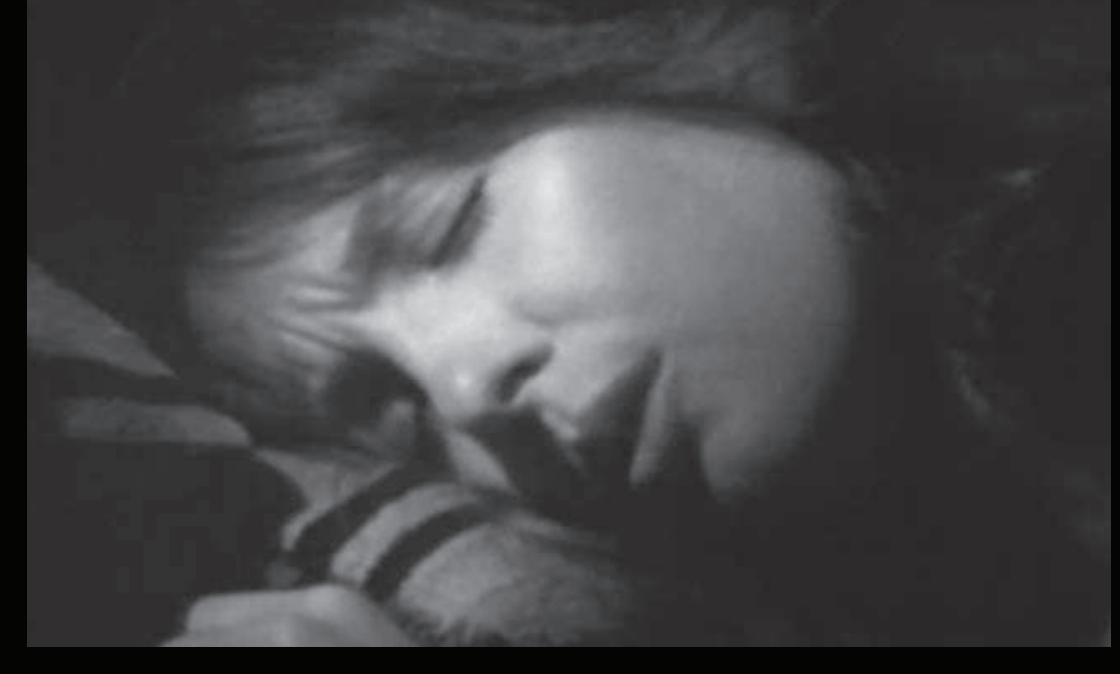

"A pesar de que la historia nos muestra

a una Therese bastante tranquila y no llega a constituir un personaje angustiado, nosotros somos sobresaltados por esta violación del raccord, por esta continuidad brutal compuesta de enfrentamientos."

Sin duda, y desgraciadamente, el filme posee algunos desaciertos. Sobre todo en el guión, elaborado, como casi siempre, por el propio Brooks. El tema de la religión que aporta la familia Dunn resulta demasiado fácil y cae en la estereotipación. La superficialidad es notoria y la religiosidad está presente solo en la utilería: en las decenas de crucifijos colgados en los rincones, en la pequeña pila de agua bendita puesta a la entrada del cuarto de Therese y en la casaca con la inscripción "Notre Dame" que orgullosamente luce el exagerado padre. La explicación del fanatismo por un sentimiento culposo frente a la hermana suicidada resulta bastante grueso.

La prolongación de esta temática religiosa crea el personaje también más débil del filme: el incomprensible James Morrisey que compone William Atherton.

Es un desacierto también la irrupción en la historia de las fantasías de Therese.
Estas restan fuerzas al filme porque tienen un inexplicable carácter festivo, que da un respiro al espectador. Estas anticipaciones imaginativas de Therese son resueltas con alguna disonante broma. El atropello y el beso de enfermo, el funeral y la repentina resurrección del padre, etcétera, son ejemplos de esta intromisión de la carcajada en un argumento lúgubre y profundo.

Buscando a Mr. Goodbar es un filme muy rico, del que se puede hablar mucho. Queda por destacar la excelente labor de Diane Keaton, quien aporta una delicada sensualidad, que emerge incluso en las secuencias con los niños sordos. Seguramente se objetará la exageración y la polarización que la historia manipula. Sin embargo, no podrá negarse que este filme revela a un Richard Brooks que, bordeando los setenta años, maneja impecablemente ese estilo lleno de "honradez y violencia" que, no por casualidad, a Godard le hacía pensar en el acto sexual.

\section{Originalmente publicado en Hablemos de cine. Año XIV. Lima, abril de 1979, pp. 53-54}

El título del filme, que repite el de la novela, alude a la búsqueda de placer de Therese. "Goodbar", literalmente "la buena barra", realiza una antología entre la búsqueda de goce sexual y el de placer que el niño siente ante las barras de dulce. Buscar a Mr. Goodbar es, así, buscar algo que es el non plus ultra del placer. Por ello, Mr. Goodbar es en la novela el nombre del bar que frecuenta Therese y está íntegramente decorado con envolturas de caramelos y dulces. 